\title{
PERBAIKAN JALAN DESA KEMBANGKUNING KECAMATAN JATILUHUR KABUPATEN PURWAKARTA
}

\author{
Lukman Nulhakim, Ade Irvan Tauvana, Widodo, Fatkur Rachmanu, Syafrizal, \\ Mokhamad Is Subekti
}

Politeknik Enjinering Indorama

lukman.nulhakim@pei.ac.id

\begin{abstract}
Roads are very important land transportation infrastructure because they support community access from one area to another. Community Service Activities in Kembangkuning Village, Jatiluhur District, Purwakarta Regency, precisely along the Kembangkuning Village road. The village road is an access in and out of the Cibinong Village community in addition to Kembangkuning Village from the Jatiluhur-Purwakarta highway. The method used is a survey conducted to find out how severe the damage and the number of damaged road locations are, after that planning makes each group's task, carrying out road repairs along the $1 \mathrm{~km}$ final stage of evaluation to find out the response of the surrounding community. Materials needed for road repairs along $1 \mathrm{~km}$ are $4 \mathrm{~m}$ of cast iron, $180 \mathrm{~kg}$ of cement, $4 \mathrm{~m}^{3}$ of sand and $10 \mathrm{~m}^{3}$ of gravel to repair 27 points of the road, where this activity was carried out for 6 hours and resulted in flat road conditions.
\end{abstract}

Keywords: road; village; kembangkuning; purwakarta

\begin{abstract}
Abstrak
Jalan merupakan prasarana transportasi darat yang sangat penting karena penunjang akses masyarakat dari suatu daerah ke daerah lain. Kegiatan Pengabdian Kepada Masyarakat di Desa Kembangkuning, Kecamatan Jatiluhur Kabupaten Purwakarta, tepatnya sepanjang jalan Desa Kembangkuning. Jalan desa tersebut merupakan akses keluar masuk masyarakat Desa Cibinong selain Desa Kembangkuning dari jalan raya Jatiluhur-Purwakarta. Metode yang digunakan yaitu survey dilakukan untuk mengetahui seberapa parah kerusakan dan jumlah lokasi jalan yang rusak, setelah itu perencanaan membuat tugas masing-masing group, pelaksanaan perbaikan jalan sepanjang $1 \mathrm{~km}$ tahap akhir evaluasi untuk mengetahui tanggapan masyarakat sekitar. Kebutuhan bahan material untuk perbaikan jalan sepanjang $1 \mathrm{~km}$ sebanyak $4 \mathrm{~m}$ besi cor, $180 \mathrm{~kg}$ semen, $4 \mathrm{~m}^{3}$ pasir dan $10 \mathrm{~m}^{3}$ kerikil untuk memperbaiki jalan sejumlah 27 titik, dimana kegiatan ini dilakukan selama 6 jam dan menghasilkan kondisi jalan sudah rata.
\end{abstract}

Kata Kunci: jalan; desa; kembangkuning; jatiluhur

\begin{tabular}{l|l|l} 
Submitted: $2021-09-13$ & Revised: 2021-10-18 & Accepted: 2021-10-26
\end{tabular}

\section{Pendahuluan}

Pembangunan jalan lingkungan merupakan bagian dari pembangunan infrastruktur desa berbasis masyarakat. Tujuan pembangunan infrastruktur desa/kecamatan berbasis masyarakat adalah untuk meningkatkan kesejahteraan masyarakat desa melalui peningkatan peran serta masyarakat desa dalam pembangunan (Mozes et al., 2020). Jalan merupakan prasarana transportasi darat yang sangat penting karena penunjang akses masyarakat dari suatu daerah ke daerah lain. Jalan lingkungan merupakan jalan umum yang berfungsi melayani angkutan lingkungan dengan ciri perjalanan jarak dekat dan kecepatan rata-rata rendah.

Kegiatan Pengabdian Masyarakat di Desa Kembangkuning, Kecamatan Jatiluhur Kabupaten Purwakarta, tepatnya sepanjang jalan Desa Kembangkuning. Jalan desa tersebut merupakan akses keluar masuk masyarakat Desa Cibinong selain Desa Kembangkuning dari jalan raya JatiluhurPurwakarta. Jalan sebagai salah satu unsur terpenting dalam kesejahteraan masyarakat di desa tersebut, dimana jalan merupakan ruang interaksi berbagai aktivitas sosial terhadap lingkungan permukiman tersebut adalah ingin menunjukkan sejauh mana interaksi sosial mempengaruhi kondisi sosial masyarakat dan kondisi fisik jalan (Yuliastuti \& Tanjung, 2011).

Kerusakan-kerusakan jalan timbul tidak disebabkan oleh satu faktor saja, tetapi juga dapat merupakan gabungan penyebab yang saling berkaitan (Yusra et al., 2018). Jenis kerusakan perkerasan jalan lentur dapat diklasifikasikan : deformasi, retak (crack), kerusakan di pinggir perkerasan, kerusakan tekstur permukaan jalan, lubang (potholes), tambalan dan tambalan galian 
utilitas (patching dan utility cut patching) (Hardiyatmo, 2015). Saat ini jalan di Desa Kembangkuning mengalami beberapa kerusakan. Terlihat pada gambar 1 kondisi salah satu jalan yang rusak disebabkan oleh beban kendaraan yang terlalu berat dan adanya genangan air hujan. Jalan rusak mengakibatkan masyarakat khususnya masyarakat kedua desa tersebut harus hati-hati dalam menjalankan kendaraannya sehingga mempengaruhi jarak tempuh lebih lama serta dapat mempercepat kerusakan salah satu komponen kendaraan yang digunakan (Subronto, 2014). Sehingga atas dasar permasalahan tersebut, kami tim dosen Program Studi Teknologi Mesin dengan mahasiswa tepatnya Himpunan Mahasiswa Mesin Politeknik Enjinering Indorama melakukan kegiatan perbaikan jalan Desa Kemangkuning Kecamatan Jatiluhur Kabupaten Purwakarta. Diharapkan setelah diperbaiki jalan, adanya peningkatan kesejahteraan masyarakat dengan maksimal khususnya Desa Kembangkuning dan pada umumnya masyarakat Purwakarta .

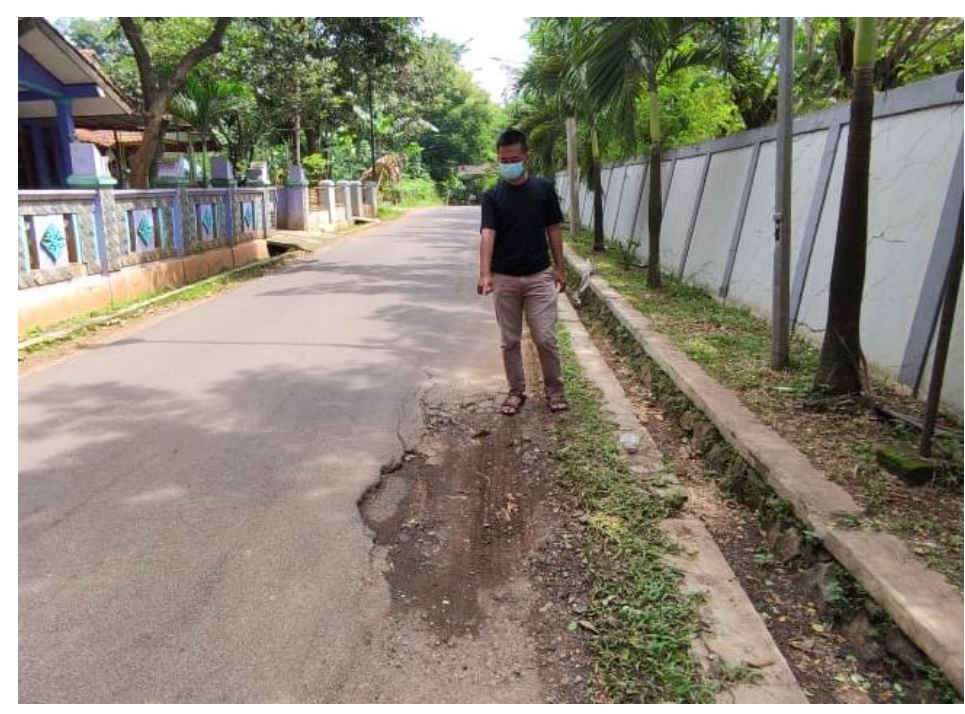

Gambar 1. Kondisi jalan Desa Kembangkuning yang rusak

\section{Metode}

Metode yang digunakan untuk kegiatan Pengabdian Kepada Masyarakat (PKM) perbaikan jalan Desa Kembangkuning Jatiluhur Purwakarat, yaitu:

1. Survey

Kegiatan ini dilakukan untuk mengetahui seberapa parah kerusakan serta berapa jumlah lokasi jalan yang rusak untuk menghitung kebutuhan bahan material yang digunakan.

\section{Perencanaan}

Perencanaan dibuat agar kegiatan ini terlaksana dengan baik, dimana setiap group mempunyai masing-masing tugas, diantaranya (1) Proses pengelasan 2 orang; (2) Proses pencampuran 4 orang; (3) Proses penambalan jalan 8 orang; (4) Traffic 2 orang; (5) Evaluasi 2 orang

3. Pelaksanaan dan tempat

Kegiatan PKM ini dilaksanakan pada hari Sabtu tanggal 21 Agustus 2021, dimana pada hari tersebut kegiatan belajar mengajar tidak ada/libur. Lokasi kegiatan ini dilakukan pada setiap titik yang rusak sampai sejauh $1 \mathrm{~km}$.

\section{Evaluasi}


Pelaksanaan evaluasi dengan melakukan pemantauan jalan yang sudah diperbaiki selama 2 hari setelah pelaksanaan di setiap titik yang sudah diperbaiki. Evaluasi ini dilakukan untuk mengetahui apakah proses yang sudah dilakukan sesuai dan kekuatan dari pencampuran antara semen, pasir dan kerikil baik atau tidak, jika tidak akan dilakukan perbaikan lagi dengan campuran yang sama tetapi dilakukan pada sore hari.

Kegiatan PKM ini melibatkan beberapa mahasiswa yang tergabung dalam Himpunan Mahasiswa Mesin (HMM) dengan tim dosen Program Studi Teknologi Mesin Politeknik Enjinering Indorama, dimana sebelumnya dilakukan koordinasi perencanaan untuk persiapan pelaksanaan. Bahan material yang digunakan diantaranya: (a) $6 \mathrm{~m}$ (1 batang) besi cor diameter $4 \mathrm{~mm}$; (b) 200 kg semen; (c) $5 \mathrm{~m}^{3}$ pasir; (d) $10 \mathrm{~m}^{3}$ kerikil; (e) Air secukupnya

\section{Hasil dan Pembahasan}

Proses pengelasan adalah pembentukan ikatan metalurgi pada sambungan logam atau logam paduan yang dilaksanakan dalam keadaan lumer atau cair dengan menggunakan energi (Tauvana et al., 2021). Proses pengelasan dibutuhkan untuk mengikat beberapa besi cor sebagai penguat (tulang) pada coran jalan menggunakan besi cor dengan diameter $4 \mathrm{~mm}$, pada gambar 2 mahasiswa melakukan proses pengelasan besi cor di Workshop Program Studi Teknologi Mesin Politeknik Enjinering Indorama.

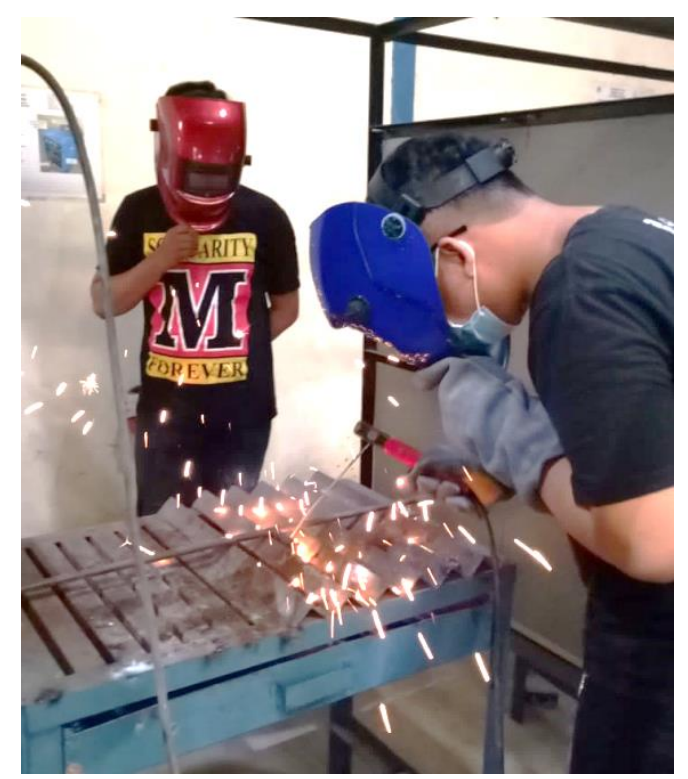

Gambar 2. Proses pengelasan besi cor

Proses pencampuran bahan material dengan campuran air, dimana kegiatan pengabdian masyarakat ini dilakukan untuk penambalan jalan menggunakan bahan campuran semen, pasir, kerikil dan air dengan perbandingan campuran 1 semen : 3 pasir : 5 kerikil (Yuono, 2017). Proses campuran semua bahan dilakukan di halaman kampus Politeknik Enjinering Indorama yang terlihat pada gambar 3, setelah itu pendistribusian dilakukan menggunakan kendaraan pick up agar dapat membawa bahan material yang sudah dicampur lebih banyak lagi. 


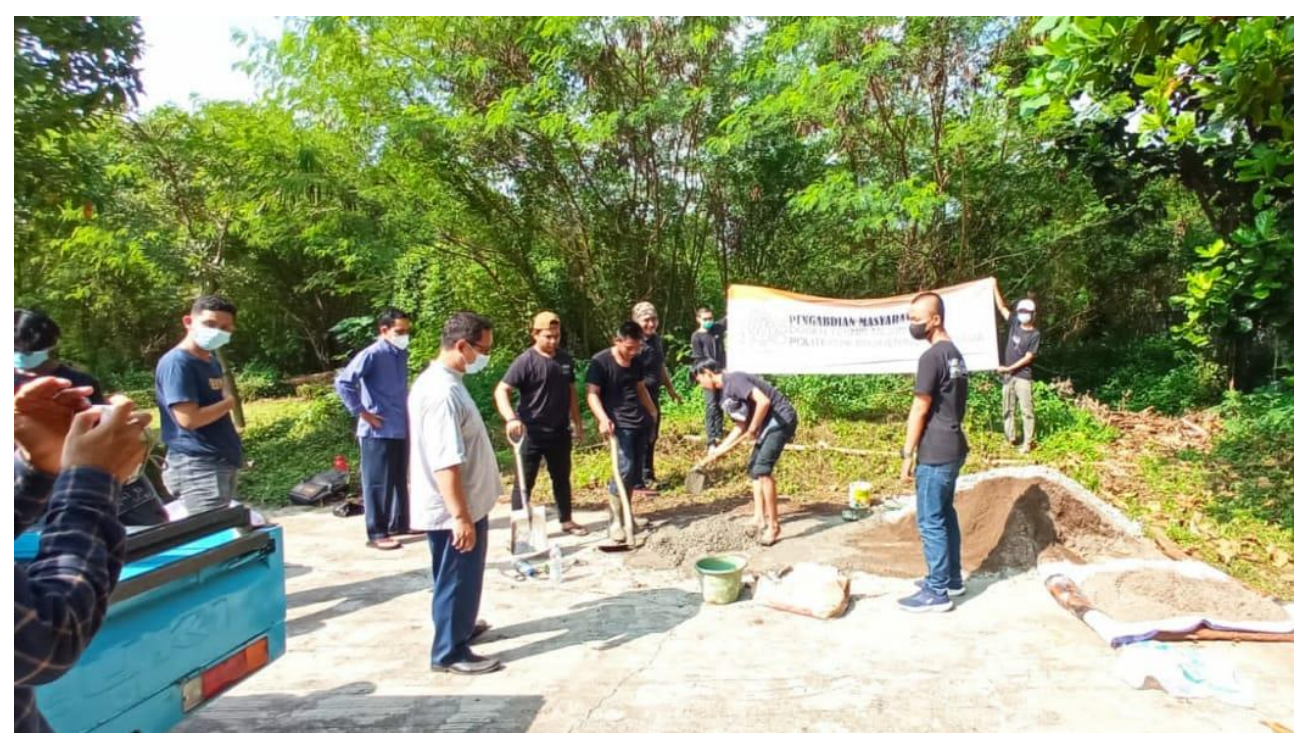

Gambar 3. Proses pencampuran semen, pasir, kerikil dan air

Kegiatan perbaikan dilakukan di setiap titik lubang, terlihat pada gambar 4, dimana lubang tersebut dibersihkan terlebih dahulu setelah itu disiram dengan air agar campuran semen dapat menempel dengan maksimal. Kemudian besi cor yang sudah disiapkan sebelumnya diletakkan pada lubang yang sudah disiram air, setelah itu dituangkan campuran semen, pasir, kerikil dan air yang sudah dicampur sebelumnya dari ember dengan menggunakan alat sekop, dan cetok (sendok semen) untuk meratakan bagian permukaan.

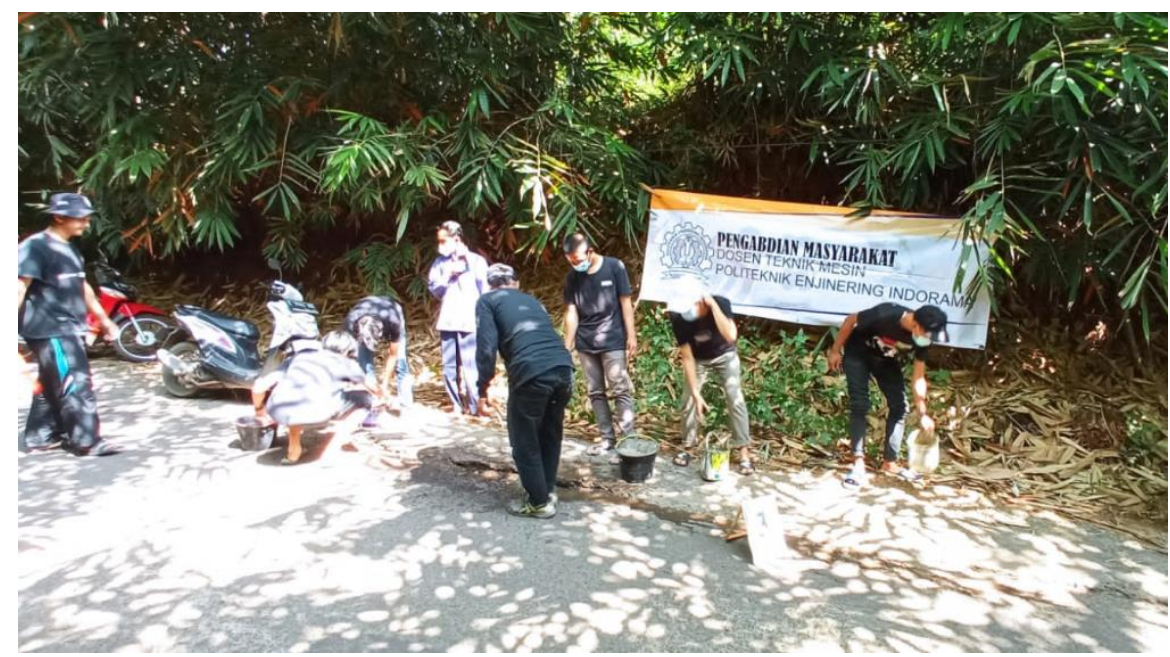

Gambar 4. Kegiatan perbaikan jalan yang rusak

Proses perbaikan jalan agar tidak mengganggu pengguna jalan maka diperlukan pengaturan jalan dengan saling bergantian, terlihat pada gambar 5 mahasiswa mengatur pengguna jalan agar tidak terjadi kemacetan pada salah satu titik, sehingga tidak menambah waktu perjalanan dengan adanya perbaiakan jalan ini. 


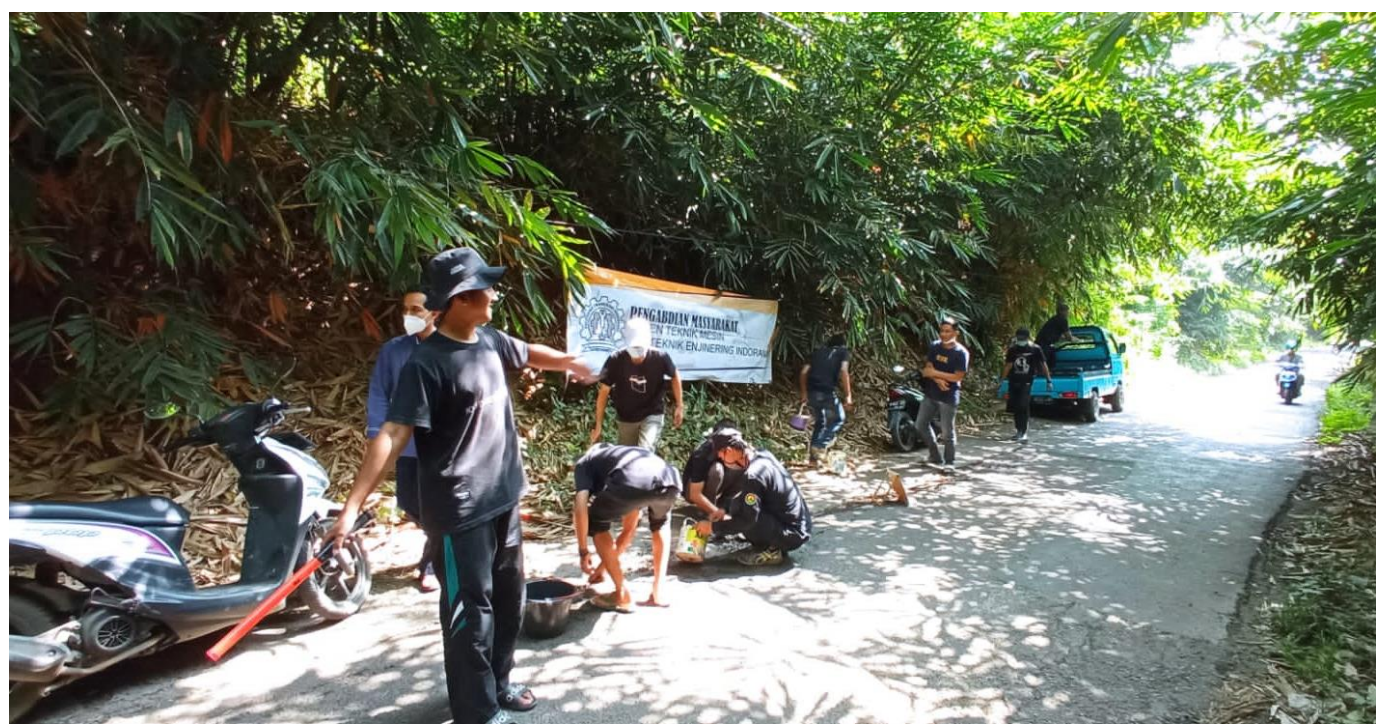

Gambar 5. Mahasiswa mengatur lalu lintas pada saat perbaikan jalan

Setelah dilakukan proses perbaikan jalan Desa Kembangkuning sepanjang $1 \mathrm{~km}$, dimulai pukul 08.00 wib sampai 15.00 wib dipotong istirahat 1 jam, dimana titik yang memerlukan perbaikan sebanyak 27 titik, dengan kedalaman mulai dari $5 \mathrm{~cm}$ sampai $20 \mathrm{~cm}$ sebagaimana terlihat pada tabel 1. Kebutuhan bahan material yang sudah digunakan disajikan pada tabel 2 untuk memenuhi kebutuhan perbaikan jalan dengan 27 titik.

Tabel 1. Ukuran dan jumlah lubang yang rusak

\begin{tabular}{ccc}
\hline No & Kedalaman $(\mathrm{cm})$ & Jumlah \\
\hline 1 & 5 & 6 \\
2 & 8 & 6 \\
3 & 9 & 5 \\
4 & 9 & 3 \\
5 & 9 & 3 \\
6 & 12 & 2 \\
7 & 14 & 1 \\
8 & 20 & 1 \\
\hline
\end{tabular}

Tabel 2. Kebutuhan bahan material

\begin{tabular}{|c|c|c|}
\hline No & Keterangan & Jumlah \\
\hline 1 & Besi cor & $4 \mathrm{~m}$ \\
\hline 2 & Semen & $180 \mathrm{~kg}$ \\
\hline 3 & Pasir & $4 \mathrm{~m}^{3}$ \\
\hline 4 & Kerikil & $10 \mathrm{~m}^{3}$ \\
\hline
\end{tabular}

Proses pemeriksaan dan pemantauan dilakukan pada setiap titik yang sudah dilakukan perbaikan. Gambar 6 menampilkan mahasiswa sedang melakukan pemeriksaan kondisi terakhir jalan yang sudah diperbaiki untuk memastikan kondisi jalan yang rusak setelah perbaikan, setelah dilakukan pemeriksaan selama 2 hari kondisi jalan yang sudah diperbaiki dengan kondisi yang baik dan layak digunakan, terlihat pada gambar 7. 


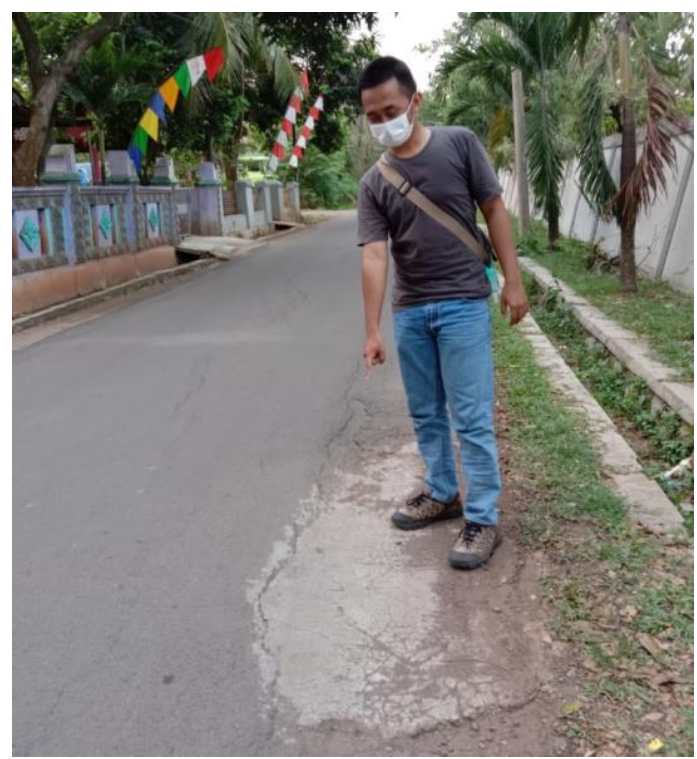

Gambar 6. Mahasiswa memeriksa kondisi jalan setelah dilakukan perbaikan

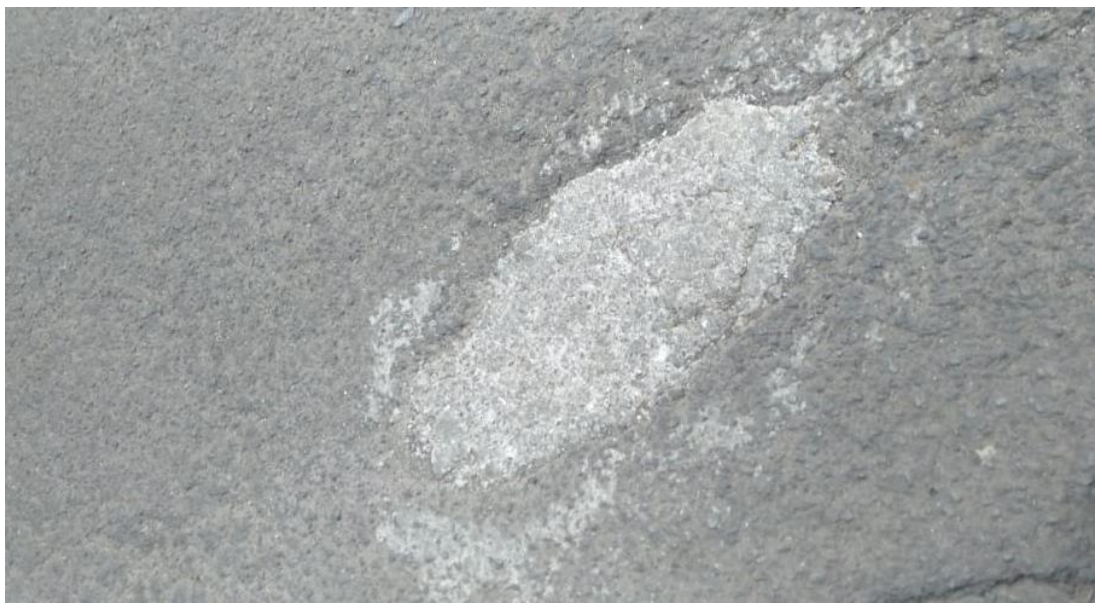

Gambar 7. Kondisi jalan setelah perbaikan

\section{Kesimpulan}

Kegiatan perbaikan jalan Desa Kembangkuning secara keseluruhan berjalan dengan lancar, dimulai dari survey, perencanaan, pelaksanaan dan evaluasi. Berdasarkan kegiatan PKM tersebut dapat diperoleh kesimpulan yaitu perbaikan jalan sepanjang $1 \mathrm{~km}$ membutuhkan bahan material sebanyak $4 \mathrm{~m}$ besi cor, $180 \mathrm{~kg}$ semen, $4 \mathrm{~m}^{3}$ pasir dan $10 \mathrm{~m}^{3}$ kerikil untuk memperbaiki jalan sejumlah 27 titik, dimana kegiatan ini dilakukan selama 6 jam dan menghasilkan kondisi jalan sudah rata kembali walaupun terlihat adanya perbedaan antara semen dan aspal. Kedepannya akan dipasang lampu penerangan sesuai masukan dari beberapa pengguna jalan dan masyarakat sekitar yang melewati jalan Desa Kembangkuning Kecamatan Jatiluhur Purwakarta.

\section{Daftar Pustaka}

Hardiyatmo, H. C. (2015). Pemeliharaan Jalan Raya. Universitas Gajah Mada.

Mozes, N., Lewaherilla, Y., Tiwery, C. J., Kristen, U., \& Maluku, I. (2020). REVITALISASI JALAN 
LINGKUNGAN PADA RT 003 / RW 04 KELURAHAN RIJALI KOTA AMBON. 1(1), 77-84.

Subronto, T. (2014). Penyebab Kerusakan Mobil, Waspadai Lubang di Jalan Pasca Musim Hujan. Carmudi Indonesia.

Tauvana, A. I., Widodo, W., Rachmanu, F., \& ... (2021). Pelatihan Pengelasan Smaw Ig Smk SeKabupaten Purwakarta, Karawang Dan Bogor. BERNAS: Jurnal ..., 2(2), 546-551. https://doi.org/10.31949/jb.v2i2.955

Yuliastuti, N., \& Tanjung, A. S. (2011). Pengaruh Jalan Lingkungan Sebagai Ruang Interaksi Sosial Terhadap Lingkungan Permukiman Bungur, Jakarta Pusat. Tataloka, 13(3), 190. https://doi.org/10.14710/tataloka.13.3.190-196

YUONO, T. (2017). Evaluasi Kuat Tekan Jalan Beton Yang Pola Pembangunannya Dengan Pemberdayaan Masyarakat. Jurnal Teknik Sipil Dan Arsitektur, 21(25).

Yusra, C. liliiza, Isya, M., \& Anggraini, R. (2018). Analisis Pengaruh Kerusakan Jalan Terhadap Kecepatan Perjalanan. Jurnal Arsip Rekayasa Sipil Dan Perencanaan, 1(3), 46-55. https://doi.org/10.24815/jarsp.v1i3.11761 